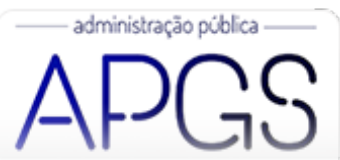

Administração Pública e Gestão Social ISSN: 2175-5787

apgs@ufv.br

Universidade Federal de Viçosa

Brasil

\title{
Determinantes de Innovación Pública en Ecuador: Un Análisis Descriptivo
}

Argothy Almeida, Anderson; González Alvárez, Nuria

Determinantes de Innovación Pública en Ecuador: Un Análisis Descriptivo

Administração Pública e Gestão Social, vol. 12, núm. 3, 2020

Universidade Federal de Viçosa, Brasil

Disponible en: http://www.redalyc.org/articulo.oa?id=351563312009

Esta obra está bajo una Licencia Creative Commons Atribución-NoComercial-SinDerivar 3.0 Internacional. 


\title{
Determinantes de Innovación Pública en Ecuador: Un Análisis Descriptivo
}

\author{
Main determinants of Public Innovation in Ecuador: Descriptive Review \\ Determinantes da inovação pública no Equador: uma análise descritiva
}

Anderson Argothy Almeida

Pontificia Universidad Católica del Ecuador, Ecuador

Redalyc: http://www.redalyc.org/articulo.oa?

laargothy@puce.edu.ec

Nuria González Alvárez

Universidad de León, España

nuria.gonzalez@unileon.es

Recepción: 12 Septiembre 2018

Aprobación: 31 Mayo 2019

Publicación: 01 Julio 2020

\section{Resumo:}

O principal objetivo deste artigo é identificar os fatores determinantes da inovação pública. Este trabalho utiliza metodologia baseada na revisão da literatura estatística e descritiva correlacional. Os dados foram colhidos no Levantamento de Atividades da Ciência, Tecnologia e Inovação (ACTI), realizado entre os anos de 2009 e 2011. Os resultados demonstram que existem 12 determinantes de inovação nas empresas públicas do Equador, classificados entre internos e externos. Além disso, existe correlação significativa entre sete determinantes, no que diz respeito à inovação pública.

Palavras-Chave: Inovação pública, determinantes da inovação, empresas públicas, gestão pública, setor público.

\section{ReSUMEN:}

El principal objetivo de este trabajo es identificar los determinantes de la innovación pública. Este trabajo utiliza metodología basada en revisión de la literatura, estadística descriptiva y análisis correlacional. Los datos corresponden a la Encuesta de Actividades de Ciencia Tecnología e Innovación (ACTI) de Ecuador para el periodo 2009 a 2011. Los resultados muestran que existen 12 determinantes de innovación en las empresas públicas de Ecuador y se clasifican en internos y externos. Además, existe correlación significativa para siete determinantes con respecto a la innovación pública.

Palabras Clave: Innovación pública, determinantes de la innovación, empresas públicas, gestión pública, sector público.

\section{Abstract:}

The main objective in this work is to identify the determinants of Public innovation. This work uses methodology based on literature review, descriptive statistics and correlational analysis. The data correspond to the Survey of Science, Technology and Innovation Activities (ACTI) of Ecuador for the period 2009 to 2011 . The results show that there are 12 determinants of innovation in public companies in Ecuador, classified as internal and external. In addition, there is a significant correlation for seven determinants with respect to public innovation

KEYWORDs: Public innovation, drivers of innovation, Public enterprises, Public Management, Public Sector.

\section{INTRODUCCIÓN}

La innovación pública es un campo de estudio reciente dentro de la economía de la innovación, ha generado una interesante corriente de investigación (Pärna \& von Tunzelmann, 2007; Hartley, 2005; Moore, 2005), debido al creciente interés del Estado en el desarrollo de la innovación. Representa una buena oportunidad para países donde existe insuficiente inversión privada en investigación y desarrollo o dónde el tamaño de los proyectos de investigación lo excluyen (Mazzucato, 2014). 
$\mathrm{Al}$ igual que en el sector privado, las investigaciones en innovación pública buscan identificar y clasificar determinantes de la innovación, en estudios sobre innovación en general la clasificación más recurrente está basada en elementos internos y externos (Love, Roper, \& Vahter, 2014; Ferreira, Fernandes, Alves, \& Raposo, 2015), situación similar ocurre en estudios de innovación pública. A pesar del interés generando, todavía no existe un marco teórico fuerte sobre determinantes de la innovación pública (Brandão \& Bruno-Faria, 2013; Arundel, Casali, \& Hollanders, 2015), a nivel de Latinoamérica hay pocos trabajos empíricos al respecto. En este sentido esta investigación tiene dos objetivos fundamentales: En primer lugar, a través de una revisión teórica profunda sobre los trabajos previos de la temática, contribuir a la literatura previa para llenar el vacío existente en la teoría sobre determinantes de la innovación pública en la región y en especial en Ecuador. Debido a lo amplio y complejo del tema aún no se ha definido cuáles son los principales determinantes de innovación pública, varios autores presentan diversas propuestas, en este trabajo los autores proponen un conjunto de determinantes basados en la revisión de la literatura más relevante; en segundo lugar, debido a la existencia de pocos trabajos empíricos sobre la temática, se propone realizar un trabajo con el uso de datos, analizando los tipos de innovación y sus determinantes en empresas públicas de Ecuador. Como se manifestó anteriormente, los pocos trabajos existentes obligan a analizar la temática desde diversos enfoques, este estudio utiliza estadística descriptiva y correlacional para probar para el caso ecuatoriano la literatura internacional revisada sobre los determinantes de la innovación en las empresas propiedad del Estado, siendo esta la principal contribución del trabajo.

La metodología del trabajo se basa en revisión de la literatura previa y un estudio empírico basado en análisis estadístico y de correlación tomando como fuente los resultados de la Encuesta Nacional de Actividades de Ciencia y Tecnología del Ecuador (ACTI), permite identificar algunos drivers internos y externos de innovación pública, así como el tipo de innovación de las empresas públicas de Ecuador.

Los determinantes seleccionados para esta investigación se basan en los trabajos de Agolla y Lill (2013); Arundel, Casali y Hollanders (2015); Fernández y Wise (2010); Hartley (2005); Luke, Verreynne y Kearing (2010); Marr (2009); Torugsa y Arundel (2015), entre otros, quienes manifiestan que la innovación pública, está condicionada por determinantes que influyen en la probabilidad de desarrollar innovación. Estos pueden ser internos o externos.

Así, a través de doce estudios de caso en gobiernos locales se identifica que la gestión de necesidades internas y externas es importante ya que presenta esquemas diferentes para la gestión de la innovación por parte de las autoridades (Bartlett \& Dibben, 2010). En cuanto al análisis detallado de factores que inciden en la innovación de las organizaciones públicas, el rol de los mandos medios es analizado a profundidad, identificando su importancia, barreras y limitaciones para la gestión de la innovación (Agolla \& Lill, 2017). Finalmente, las investigaciones previas destacan diferentes tipos de relación entre determinantes e innovación pública (Arundel \& Huber, 2013; Torugsa \& Arundel, 2015; Walker, 2008; Agolla \& Lill, 2013). Uno de los trabajos recientes plantea un modelo basado en tres elementos: Liderazgo, clima y cultura organizacional y barreras. La relación éntrelos tres elementos es lo que genera innovación en el sector público (Moussa, Mcmurray, y Muenjohn 2018); otros trabajos centrados en el estudio de las condiciones que permiten mejora en los países en desarrollo se han enfocado en el estudio de la Inversión Extranjera Directa (Jibir \& Abdu, 2017).

El presente trabajo está distribuido de la siguiente manera. La sección 2, incluye la revisión teórica y conceptual de cada uno de los determinantes de la innovación, divididos en internos y externos además de las hipótesis de trabajo. La sección 3, muestra la metodología utilizada, número de casos y otros detalles de la encuesta ACTI. En la sección 4, se presentan y discuten los resultados obtenidos a partir del tratamiento de datos. Finalmente, la sección 5, incluye las conclusiones finales del estudio y las futuras líneas de investigación. 


\section{Marco teórico: Drivers de inNovación pública}

La revisión de la literatura previa clasifica de diferentes formas los determinantes de la innovación, Dunleavy y Margetts (2006) identifican determinantes internos y externos, impactos y barreras para la innovación pública; otros estudios analizan características ambientales (externas) y organizacionales (internas) en el proceso de innovación (Damanpour \& Schneider, 2006; Walker, 2008). Existen factores que contribuyen a la diseminación de innovación, en las instituciones públicas brasileñas, la innovación se ve influenciada por actores e instituciones internas y externas (Farah, 2008); Vigoda-Gadot, Shoham, Schwabsky y Ruvio (2008) analizan desde la perspectiva de los ciudadanos la relación entre antecedentes y resultados de innovación, si bien no clasifican los factores, tienen en cuenta elementos propios y ajenos de la institución; Luke et al. (2010) mencionan drivers externos y facilitadores internos de la innovación pública; Kim (2010) y Leagreid, Roness y Verhoest (2011) identifican características estructurales, de gestión y culturales, además, ambientales o de entorno que afectan la innovación pública; Agolla y Lill (2013) los clasifican en internos y externos, identificando cinco y ocho factores respectivamente; Bloch y Bugge (2013) analizan gestión interna, trabajadores, ciudadanía, usuarios y proveedores, fuerzas políticas y otras organizaciones, como factores que inciden sobre la innovación pública; Arundel et al. (2015) analizan fuentes de ideas, información, determinantes políticos y estrategias de apoyo a la innovación pública, teniendo en cuenta niveles internos y externos de la organización.

\section{Drivers Internos}

Este tipo de determinantes representan atributos internos de las instituciones públicas, dan soporte a las actividades de innovación y emprendimiento en las organizaciones (Luke et al., 2010); son el conjunto de competencias[i] técnicas, en un contexto específico de variables que ayudan a explicar la tasa de innovación de las organizaciones públicas (Arduini et al., 2010), permiten incubación de ideas que pueden convertirse en innovaciones (Agolla \& Lill, 2013); afectan la capacidad de la organización para absorber conocimiento externo (Love, Roper, \& Vahter, 2014).

Así, en este trabajo se seleccionan aquellos determinantes que han sido más estudiados en la literatura y con mayor impacto en las instituciones. Son ellos: Tamaño de la organización (Fernández \& Wise, 2010; Palmer \& Dunford, 2001); estructura organizacional (Palmer \& Dunford, 2001; Laegreid, Roness, \& Verhoest, 2011; Kim, 2010); estrategia interna de apoyo a la innovación (Borins, 2001; Kim, 2010; ANAO 2009; Bysted y Jespersen 2014); liderazgo (Vigoda-Gadot et al., 2008; Agolla \& Lill, 2013; Borins, 2002); trabajadores y mandos medios (Saari, Lehtonen, \& Toivonen, 2015).

\section{Tamaño de la organización}

El efecto tamaño de la institución ha merecido especial atención, es un tema de debate entre académicos e investigadores (Fernández \& Wise, 2010; Palmer \& Dunford, 2001), puede ser relacionado con otros factores haciendo que la institución sea más abierta o resistente al cambio (Fernández \& Wise, 2010).

Es determinante directo en tres de cuatro fases de adopción de innovaciones (Bingham, 1978), tiene efecto positivo debido a la posibilidad de movilizar mayores recursos (Damanpour \& Schneider, 2006; Damanpour, Walker, \& Avellaneda, 2009); mayor tamaño aumenta la probabilidad de desarrollar innovaciones (European Commission, 2010); por el contrario, un mayor tamaño también puede tener efectos negativos sobre la innovación (Lonti \& Verma, 2003); el tamaño no es determinante significativo en la decisión de adoptar innovaciones dentro de las instituciones públicas (Boyne, Gould-Williams, Law, \& Walker, 2005; Walker, 2006; Walker, 2008). 
Existe ambigüedad respecto al efecto del tamaño en la innovación pública, sin embargo, destaca su importancia como determinante de la innovación pública ya que se encuentra presente en varios trabajos relacionados y es medido diferentes maneras.

Hipótesis 1: Existe una correlación significativa entre el tamaño de la organización y la innovación en las empresas públicas de Ecuador.

\section{Estructura organizativa}

Representa, flexibilidad y capacidad de respuesta, jerarquía, autonomía, burocratización, integración, limites y prácticas de gestión que poseen las instituciones (Palmer \& Dunford, 2001; Laegreid et al., 2011; Kim, 2010), capacidad para movilizar, desplegar y utilizar recursos para brindar servicios a ciudadanos en general y en especial en lugares alejados, desfavorecidos y expuestos (United Nations, 2006; Alberti \& Bertucci, 2006).

Para Bingham (1978), la estructura está relacionada con innovación de procesos. Para la innovación, son importantes la reorganización institucional y una correcta estructura organizativa (Damanpour \& Schneider, 2006), una estructura jerárquica excesiva es negativa para la comunicación e innovación generando resistencia al cambio (Kim, 2010). La flexibilidad, autonomía y descentralización promueve la innovación y el emprendimiento (Kim, 2010; Laegreid et al., 2011; Lonti y Verma 2003; Mulgan 2007; Bysted y Jespersen 2014). Para Pärma y von Tunzelman (2007), la jerarquía es poco importante para la innovación, al igual que la flexibilidad (Djellal \& Gallouj, 2012). Las organizaciones públicas son generalmente poco flexibles (Djellal \& Gallouj, 2012). Para Palmer y Dunford (2001) la centralización[ii] de decisiones tiene correlación positiva con la innovación.

No hay acuerdo sobre el efecto (positivo o negativo) de la estructura organizacional ante la innovación, sin embargo, destaca su importancia ya que es un tema de debate recurrente en los trabajos de innovación. Se considera que las empresas públicas ecuatorianas realizan modificaciones en su estructura organizativa.

Hipótesis 2: Los cambios en la estructura organizacional tienen correlación significativa con la innovación en las empresas públicas de Ecuador.

\section{Estrategia de apoyo a la innovación}

Hace referencia a las acciones realizadas por una organización con el objetivo de estimular la creatividad e innovación (Morcillo, Rodríguez-Antón, y Rubio 2007); ayuda a la correcta definición de innovación en la institución y las áreas involucradas, permite enfocar esfuerzos, precisar la tecnología a usar y la forma de medir los avances logrados (Agolla \& Lill, 2013). Puede ser el apoyo de las autoridades, recompensas, incentivos, inversiones etc. (Borins 2001; Kim 2010; ANAO, 2009; Bysted \& Jespersen, 2014); tiene efecto positivo para el desarrollo de innovaciones (Laegreid et al., 2011; Moussa, Mcmurray, \& Muenjohn, 2018), reduce el incentivo a actividades burocráticas (Aubert et al., 2010); la ausencia de incentivos incrementa la aversión al riesgo (Torugsa \& Arundel, 2015). Potts y Kastelle (2010) proponen comparar los incentivos y recompensas de la innovación pública con los incentivos de la actividad académica, en lugar de compararlos con los de la empresa privada, en el caso de la academia y el sector público los fines son más altruistas que monetarios.

Otras estrategias de apoyo, orientación a resultados y desempeño por objetivos (Lonti \& Verma, 2003; Kim, 2010), herramientas de gestión y fomento de la cultura de innovación (Pärna \& von Tunzelmann, 2007), generación de espacios creativos (Mulgan \& Albury, 2003; Mulgan, 2007; Torugsa \& Arundel, 2015), desarrollo de la creatividad, prototipos y pilotos, escalamiento y gestión del riesgo, a pesar de ser estrategias privadas pueden funcionar en organizaciones públicas (Mulgan, 2007; Torugsa \& Arundel, 2015). 
La literatura sobre innovación pública al igual que la privada reconoce la importancia que tiene el apoyo interno a la innovación, este determinante tiene efecto positivo en el desarrollo de innovaciones y puede ser propiciada por diferentes herramientas tal y como muestra la literatura previa.

Hipótesis 3: Las estrategias de apoyo a la innovación tiene correlación significativa con la innovación en las empresas públicas de Ecuador.

\section{Liderazgo}

Se refiere a la visión de las autoridades de la organización, un cambio de percepción, la forma de gestionar la organización para lograr desarrollar al máximo el potencial innovador (Vigoda-Gadot et al., 2008; Agolla \& Lill, 2013; Borins, 2002); es un proceso emergente de acciones a nivel de clima y cultura organizacional (Fernández \& Wise, 2010); hace referencia a la formación de una visión para el futuro, comunicada y comprometida en todos los niveles (Sarros, Cooper, \& Santora, 2008). Incluye un conjunto de cualidades (Agolla \& Lill, 2013). Existe fuerte relación entre innovación y liderazgo (Borins, 2002; Borins, 2001) ya que las organizaciones innovadoras tienden a utilizar liderazgo estratégico para lograr una dirección innovadora y potenciar la innovación (Sarros, Cooper, \& Santora, 2008; Moussa, Mcmurray, \& Muenjohn, 2018); el liderazgo está positivamente relacionado con la adopción de programas de innovación y conocimiento (Moon \& de Leon, 2001; ANAO, 2009) y resulta importante para la innovación al igual que la actitud de las autoridades (Bloch \& Bugge, 2013; Damanpour \& Schneider, 2006).

Otros trabajos concluyen que la orientación política de las autoridades es ambigua y no influye en la adopción de innovaciones (Moon \& de Leon, 2001); en este caso se considera que la actitud de las autoridades no es significativa en la decisión de innovar (Boyne et al., 2005), igual que la edad y género de las autoridades (Damanpour \& Schneider, 2006).

Así, la literatura previa destaca la importancia del liderazgo para el desarrollo de la innovación en las instituciones públicas. Esta relación se recoge en la siguiente hipótesis:

Hipótesis 4: El liderazgo tiene correlación significativa con la innovación en las empresas públicas de Ecuador.

\section{Trabajadores y mandos medios}

Los trabajadores y mandos medios de una organización suelen poseer la capacidad de impulsar y transmitir ante las autoridades, necesidades de innovación de usuarios y ciudadanos, mientras que los mandos medios ayudan en la gestión para desarrollo de la innovación (Saari, Lehtonen, \& Toivonen, 2015); los trabajadores tienen impacto positivo en el desarrollo de innovaciones, apoyan y permiten cumplir objetivos y muchas innovaciones son logradas a través de estos (Borins, 2002); la motivación de los trabajadores afecta a los resultados de innovación ya que existe relación entre satisfacción del trabajador e innovación (Palmer \& Dunford, 2001), tipo de contrato, clima organizacional e innovación (Montes, Moreno, \& Fernández, 2004; Moussa, Mcmurray, \& Muenjohn, 2018).

De esta forma, los trabajadores, mandos medios y diversidad de personal son fuente de innovación (Mulgan, 2007; Mulgan \& Albury, 2003; Torugsa \& Arundel, 2015), adicionalmente, las autoridades principales tienen fuerte influencia para el desarrollo de la innovación en los mandos medios, a través del desarrollo de políticas adecuadas que apoyen a la innovación (Agolla \& Lill, 2017); la educación, capacitación y capacidad de aprendizaje de los trabajadores están relacionadas positivamente con la innovación (Marr, 2009; Sánchez \& Castrillo, 2006; Bingham, 1978; Lonti \& Verma, 2003); el conocimiento y capacitación de los trabajadores son recursos intangibles importantes (Agolla \& Lill, 2013; Sánchez \& Castrillo, 2006). Sin embargo la verdadera cuestión está en gestionar adecuadamente estos recursos en beneficio de la innovación 
y la transformación de conocimiento tácito en codificado para ser difundido e incorporado (Nonaka \& Takeuchi, 1995).

Los trabajadores y mandos medios son importantes para la innovación en las organizaciones públicas. Están relacionados positivamente al igual que el gasto en capacitación. Estas ideas se recogen en las siguientes hipótesis:

Hipótesis 5: La capacitación de los trabajadores tiene correlación positiva significativa con la innovación en las organizaciones públicas.

Hipótesis 6: La salud y seguridad de los trabajadores tiene correlación positiva significativa con la innovación en las organizaciones públicas.

\section{Drivers Externos}

Comprende factores más allá, usualmente desconsiderados por una organización individual que se encuentra en situación de operación y determinan oportunidades, amenazas y restricciones (Pearce \& Robinson, 2003), las organizaciones públicas analizan el entorno externo, otras organizaciones gubernamentales, gobiernos y empresas en otros países (Agolla \& Lill, 2013).

Dentro de los drivers internos, este trabajo analiza aquellos que destacan su importancia en la literatura previa: Gobierno, entorno político y legal (Vigoda-Gadot et al., 2008; Walker, 2008; Agolla \& Lill, 2013; Fernández \& Wise, 2010); Factores sociales y demográficos (Agolla \& Lill, 2013; Marr, 2009; UN Millennium Project, 2005); Tecnología (Arduini et al., 2010; Pärna \& von Tunzelmann, 2007); Entorno económico y variaciones de presupuesto (Marr, 2009; Agolla \& Lill, 2013; Potts \& Kastelle, 2010; Mulgan \& Albury, 2003); Cooperación, Acuerdos y Colaboraciones (Goh, 2005; Bugge, Mortensen, \& Bloch, 2011; Bommert, 2010; OECD, 2010).

\section{Gobierno: entorno político y legal}

Se refiere a la capacidad del gobierno central para modificar el entorno legal, incentivos y de inversiones para fomentar la innovación a nivel estatal y empresarial (Vigoda-Gadot et al., 2008; Walker, 2008; Agolla \& Lill, 2013; Fernández \& Wise, 2010), proteger los intereses sociales de los fallos de mercado (Saari, Lehtonen, \& Toivonen, 2015), desarrollar nuevas ideas, creando o incrementando el valor público (Potts \& Kastelle, 2010), es ampliamente mencionado en la literatura (Torugsa \& Arundel, 2015; Lonti \& Verma, 2003), el gobierno genera el marco que incide en los desequilibrios de poder, relaciones sociales y de poder priorizando la inversión en megaproyectos tradicionales y tecnológicos (Agolla \& Lill, 2013; Mazzucato, 2014).

Es importante para el desarrollo de innovación, mediante compromisos asumidos con la sociedad (Bingham, 1978; Pärna \& von Tunzelmann, 2007), cambio de prioridades (Lonti \& Verma, 2003), política nacional y social (Porter \& Stern, 2001), influencia política (Kim, 2010; Arundel et al., 2015), régimen político administrativo (Laegreid et al., 2011), reformas estructurales en educación, políticas de capacitación, emprendimiento, fiscales estandarización de producto y servicios, apoyo a instituciones públicas de investigación, políticas para la creación de redes y espacios de conocimiento, infraestructura y oferta de tecnología (OECD, 2010; Agolla \& Lill, 2013).

El gobierno puede influir positivamente en la innovación a nivel público y privado, para ello tiene a disposición diversidad de herramientas que son utilizadas acorde a las prioridades de desarrollo y que van más allá de su rol tradicional como generador del marco legal. Las hipótesis 7 y 8 recogen estas ideas.

Hipótesis 7: El conocimiento de los programas gubernamentales de apoyo a la innovación tiene correlación significativa con la innovación.

Hipótesis 8: El apoyo financiero gubernamental tiene correlación significativa con la innovación. 


\section{Factores sociales y demográficos}

Incluye características demográficas y culturales del entorno donde las instituciones operan (Agolla \& Lill, 2013; Marr, 2009), presiones de los factores sociales[iii] obligan al gobierno a buscar soluciones innovadoras, incrementando la efectividad y eficiencia de los servicios públicos (UN Millennium Project, 2005; Agolla \& Lill, 2013). La comunidad (demandas y participación de los ciudadanos) es importante para la innovación pública, tiene efectos positivos al igual que el tamaño de la población (Borins, 2001; Lonti \& Verma, 2003; Walker, 2006; Damanpour, Walker, \& Avellaneda, 2009; Moon \& de Leon, 2001), en la literatura previa se muestran algunos datos al respecto (Bloch \& Bugge, 2013; Bugge, Mortensen, \& Bloch, 2011). Trabajos relacionados hablan de acciones a favor del ambiente como importantes para la innovación (Dunleavy \& Margetts, 2006; Agolla \& Lill, 2013); otros trabajos indican una relación inversa entre tamaño poblacional e innovación (Boyne et al., 2005; Damanpour \& Schneider, 2006).

Los factores sociales y demográficos son diversos y pueden afectar el desarrollo de innovaciones, aunque la literatura mayoritariamente habla de relación positiva, existen trabajos que indican lo contrario. Para el caso ecuatoriano se espera que este sea un determinante importante para las empresas públicas.

Hipótesis 9: La reducción del impacto ambiental como objetivo de innovación tiene correlación significativa con la innovación.

\section{Tecnología}

Este driver externo hace referencia a la adquisición, implementación, gestión de nueva tecnología para creación de productos o servicios para usuarios y ciudadanos (Arduini et al., 2010; Pärna \& von Tunzelmann, 2007), acceso a activos tecnológicos incluyendo equipamiento y el proceso de innovación (Cruz \& Paulino, 2013), en la mayoría de los países las diferencias de productividad han sido explicadas por el rol que juega la tecnología (Keller, 2004), el aprendizaje tecnológico es fundamental para el desarrollo de innovaciones (Mulgan \& Albury, 2003), los cambios tecnológicos explican la innovación (Lonti \& Verma, 2003), permiten el desarrollo de otras formas de innovación (procesos, organizacional, servicios, sistemas de interacción) en la organización (Koch \& Hauknes, 2005; Arundel et al., 2015), nuevos o mejorados bienes y servicios (Marr, 2009), nuevas formas de acceso a servicios (Marr, 2009; Goh, 2005) y reducen costes (Agolla \& Lill, 2013).

Cuando se habla de innovación la tecnología y su acceso es fundamental para determinar el rumbo innovador de una organización. En este sentido se espera que las organizaciones realicen las inversiones adecuadas para adquisición de tecnología incorporada y desincorporada.

Hipótesis 10: La adquisición de tecnología tiene correlación significativa con la innovación.

\section{Entorno económico y variaciones de presupuesto}

Las magnitudes macroeconómicas (tasa de crecimiento, tasa de interés, tasa de cambio, inflación, empleo, etc.) tienen efecto directo sobre la institución pública, incremento o reducción del presupuesto fiscal; el ciudadano, afectando la demanda y oferta de servicios (Marr, 2009; Agolla \& Lill, 2013). El sector público está dirigido por principios económicos de eficiencia, busca minimizar la perdida y maximizar la entrega de servicios con un presupuesto finito (Potts \& Kastelle, 2010; Mulgan \& Albury, 2003). Existe relación directa entre situación económica e innovación pública (Bingham, 1978) y adopción de innovaciones (Damanpour \& Schneider, 2006).

Las crisis económicas conllevan restricciones presupuestarias que incrementan la capacidad de innovación (Borins, 2001), innovar para enfrentar las presiones por reducir gastos y ser más eficientes (Mulgan \& Albury, 2003; Saari, Lehtonen, \& Toivonen, 2015), las restricciones presupuestarias son significativas para explicar 
la innovación (Lonti \& Verma, 2003).Por el contrario, un entorno económico restrictivo es obstáculo para la innovación al igual que el sistema presupuestario de las instituciones públicas, debido a la imposibilidad de transferir el superávit presupuestario de un año a otro (Vigoda-Gadot et al., 2008).

El entorno económico determina muchos de los resultados de innovación a nivel privado como público. Sin embargo, la forma de enfrentar una restricción presupuestaria dependerá de la organización, no existe acuerdo en la literatura respecto a si beneficia a la innovación o la restringe.

Hipótesis 11: La falta de fondos en las empresas públicas tienen correlación significativa con la innovación.

\section{Cooperación, Acuerdos y Colaboraciones}

Se refiere a la interacción entre varios agentes en un ambiente que facilita la innovación (Goh, 2005). La innovación no depende del desempeño individual del sector público y privado, universidades, institutos de investigación o regulaciones del gobierno, sino del trabajo conjunto (Goh, 2005; Bugge, Mortensen, \& Bloch, 2011; Bommert, 2010; OECD, 2010).

Favorecen a la innovación, las relaciones entre instituciones y sectores profesionales (Bingham, 1978), las redes de trabajo (networking), colaboración de usuarios finales y otras instituciones públicas (Mulgan \& Albury, 2003; Bugge, Mortensen, \& Bloch, 2011; Bloch \& Bugge, 2013), uniones y asociaciones (Damanpour \& Schneider, 2006), socios estratégicos (Arundel et al,, 2015), academia y organizaciones no gubernamentales (Mulgan, 2007; ANAO, 2009; European Commission, 2010), permite la resolución de problemas persistentes o emergentes, la creación de valor, la superación de barreras, el aprovechamiento de recursos, la cooperación de equipos técnicos y la difusión de tecnología (Goh, 2005; OECD, 2010; Sorensen \& Torfing, 2012; Szkuta, Pizzicannella, \& Osimo, 2014; Bommert, 2010)

Es importante para el desarrollo de la innovación y así lo ratifican los diversos autores, tienen efectos positivos y puede realizarse con múltiples socios. Se espera que las empresas públicas tengan relaciones de cooperación.

Hipótesis 12: La cooperación con diferentes actores tiene correlación significativa con la innovación.

\section{Metodología}

Este trabajo utiliza la base de datos de la primera Encuesta Nacional de Actividades Ciencia Tecnología Innovación del Ecuador (ACTI), realizada por el Instituto Nacional de Estadísticas y Censos (INEC) y la Secretaría Nacional de Educación Superior Ciencia Tecnología e Innovación (SENESCYT), publicada en el año 2014, con información actualizada al año 2011. Cuenta con una muestra de 2815 organizaciones, divididas en 2749 (97,66\%) empresas privadas y 66 (2,34\%) empresas públicas.

Utilizamos el software estadístico y econométrico STATA, para tratamiento, análisis y organización de la data. Se seleccionaron preguntas de la encuesta y se tabularon, permitieron un primer acercamiento descriptivo de los determinantes de la innovación (tablas 1, 2 y 3). Estas preguntas sirven de insumo para la construcción de variables para el análisis de correlación (Tabla 4). Dadas las características de las variables utilizadas para el análisis, se ha utilizado una correlación no paramétrica, mediante la correlación de Spearman, la misma que se ajusta mejor a los datos disponibles.

\section{Variables}

Innovación: Variable dicotómica compuesta por empresas que realizaron al menos un tipo de innovación (producto, proceso, servicio); el nivel de novedad no ha sido tomado en cuenta al igual que la innovación incremental. 
Tamaño de la empresa: Se mide de acuerdo al número de trabajadores mediante una escala (1=pequeña, $2=$ mediana, $3=$ grande).

Estructura organizacional: Variable dicotómica compuesta por las empresas que realizaron cambios significativos en su estructura y contrastada por el tipo de cambio realizado.

Estrategia de apoyo a la innovación: Variable dicotómica compuesta por empresas que realizan gastos internos y externos en investigación y desarrollo.

Liderazgo: La pregunta original sobre la importancia del área administrativa para la innovación constaba de cuatro respuestas ( $1=$ alta, $2=$ media, $3=$ baja y $4=$ no importante $)$ pero ha sido simplificada para obtener un indicador ( $1=$ importante, $0=$ no importante).

Trabajadores y mandos medios: Utiliza dos variables, empresas que han realizado gastos en capacitación $(1=\mathrm{Si}, 0=\mathrm{No})$ y un indicador creado a partir de la pregunta "importancia del objetivo de innovación mejorar la salud y seguridad de los trabajadores" cuyas respuestas originales ( $1=$ alta, $2=$ media, $3=$ baja y $4=$ no relevante), se modificaron ( $1=$ importante, $0=$ no importante).

Gobierno: Contiene dos variables, la primera un indicador del conocimiento de las empresas sobre los seis programas gubernamentales de apoyo a la innovación $(1=$ conoce, $0=$ no conoce $)$. La segunda corresponde a empresas que han recibido apoyo financiero adicional por parte del gobierno para desarrollar proyectos de innovación $(1=\mathrm{si}, 0=$ no).

Factores sociales: Es un indicador sobre la importancia de reducir el impacto ambiental como objetivo de innovación ( $1=$ importante, $0=$ no importante).

Tecnología: Es un indicador dicotómico $(1=s i, 0=$ no), para las empresas que adquirieron algún tipo de tecnología (maquinaria y equipo, software, hardware, tecnología desincorporada).

Entorno Económico: Mide la importancia de la falta de fondos como obstáculo a la innovación, simplificando la respuesta original $(1=$ alta, $2=$ media, $3=$ baja y $4=$ no relevante), a $(1=$ importante, $0=$ no importante).

Cooperación: Es un indicador de las empresas que cooperaron con al menos uno de los diferentes agentes externos ( $1=$ cooperó, $0=$ no cooperó).

A continuación, se presentan los resultados del análisis descriptivo y de correlación de los determinantes de la innovación publica en Ecuador.

\section{Discusión Y RESULTADOS}

Esta sección recoge los resultados obtenidos, primero se muestra información descriptiva de las empresas públicas de Ecuador respecto a: innovación (Tabla 1), determinantes internos (Tabla 2), externos (Tabla 3), luego analizamos la existencia de correlación entre variables (Tabla 4). 
Tabla 1. Innovación en las Instituciones públicas

\begin{tabular}{|c|c|c|}
\hline \multicolumn{2}{|l|}{ Tipo de innovación: } & \% Porcentaje \\
\hline \multirow{2}{*}{ Innovación de un Bien nuevo } & No & $94,9 \%$ \\
\hline & Si & $5,1 \%$ \\
\hline \multirow{3}{*}{ Novedoso para: } & La empresa & $32,9 \%$ \\
\hline & El mercado nacional & $67,1 \%$ \\
\hline & El mercado internacional & $0,0 \%$ \\
\hline \multirow{2}{*}{ Innovación de un Servicio nuevo } & No & $92,2 \%$ \\
\hline & $\mathrm{Si}$ & $7,8 \%$ \\
\hline \multirow{3}{*}{ Novedoso para: } & La empresa & $53,9 \%$ \\
\hline & El mercado nacional & $35,4 \%$ \\
\hline & El mercado internacional & $10,7 \%$ \\
\hline \multirow{2}{*}{$\begin{array}{l}\text { Innovación lograda de Proceso } \\
\text { Nuevo }\end{array}$} & No & $82,3 \%$ \\
\hline & $\mathrm{Si}$ & $17,7 \%$ \\
\hline \multirow{3}{*}{ Novedoso para: } & La empresa & $79,5 \%$ \\
\hline & El mercado nacional & $15,7 \%$ \\
\hline & El mercado internacional & $4,7 \%$ \\
\hline \multicolumn{3}{|l|}{ Innovación Incremental: } \\
\hline \multirow{2}{*}{$\begin{array}{l}\text { Innovación de un Bien } \\
\text { significativamente mejorado }\end{array}$} & No & $94,1 \%$ \\
\hline & $\mathrm{Si}$ & $5,9 \%$ \\
\hline \multirow[t]{3}{*}{ Novedoso para: } & La empresa & $28,2 \%$ \\
\hline & El mercado nacional & $71,8 \%$ \\
\hline & El mercado internacional & $0,0 \%$ \\
\hline \multirow{2}{*}{$\begin{array}{l}\text { Innovación de un Servicio } \\
\text { significativamente mejorado }\end{array}$} & 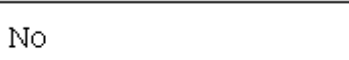 & $67,6 \%$ \\
\hline & $\mathrm{Si}$ & $32,4 \%$ \\
\hline \multirow[t]{3}{*}{ Novedoso para: } & La empresa & $68,5 \%$ \\
\hline & El mercado nacional & $25,3 \%$ \\
\hline & El mercado internacional & $6,2 \%$ \\
\hline \multirow{2}{*}{$\begin{array}{l}\text { Innovación lograda de Proceso } \\
\text { significativamente mejorado }\end{array}$} & No & $71,2 \%$ \\
\hline & $\mathrm{Si}$ & $28,8 \%$ \\
\hline \multirow[t]{3}{*}{ Novedoso para: } & La empresa & $71,5 \%$ \\
\hline & El mercado nacional & $28,5 \%$ \\
\hline & El mercado internacional & $0,0 \%$ \\
\hline
\end{tabular}

En referencia a los tipos de innovación, la innovación puede ser de producto o servicio, proceso, marketing y organización; con diferentes niveles de novedad (OECD, 2005). Así, 5,1\% de las empresas realizan innovaciones de producto, sus innovaciones son novedosas para el mercado nacional $67,1 \%$ y para la empresa $32,9 \%$. Estos resultados indican que a nivel de producto las empresas públicas son seguidoras o adoptadoras de innovación de producto (Rogers, 1976; OECD, 2005).

En 7,8\% de las empresas existen innovaciones de servicio; el nivel de novedad varía entre: empresa 53,9\%, nacional $35,4 \%$ e internacional $10,7 \%$. Cabe destacar la importancia que tiene el desarrollo de innovaciones a nivel internacional.

La innovación de proceso está presente en $17,7 \%$ de las empresas. La mayoría de estas innovaciones son novedosas para la organización 79,5\%, nivel nacional 15,7\% e internacional 4,7\%.

Así, los resultados muestran que existen innovaciones destacables a nivel de servicio y proceso en las empresas públicas de Ecuador, se pueden considerar como radicales (Schumpeter, 1947), debido al nivel de novedad de escala internacional, en muchos casos responden a la inclusión de cambios en tecnología e innovaciones de producto (Windrum \& García, 2008).

Existe innovación incremental (Schumpeter, 1947; Windrum \& García, 2008), en las empresas públicas ecuatorianas. Así, 5,9\% de las empresas encuestadas ha realizado mejoras en los bienes producidos, siendo novedoso para el mercado nacional $71,8 \%$ y para la empresa $28,2 \%$, no existen mejoras novedosas a nivel internacional. 
Los servicios han mejorado significativamente en $32,4 \%$ de las organizaciones, siendo novedosos para la empresa y mercado nacional en $68,5 \%$ y $25,3 \%$ respectivamente. Adicionalmente, para $6,2 \%$ de las organizaciones las mejoras de servicio fueron novedosas a nivel internacional.

Existe mejora de procesos en 28,8\% de las empresas, a nivel de empresa $71,5 \%$ y mercado nacional $28,5 \%$, no existen mejoras novedosas a nivel internacional.

Tabla 2. Determinantes Internos

\begin{tabular}{lc}
\hline Tamaño de la empresa: por número de trabajadores & $63,0 \%$ \\
\hline Pequeña Empresa & $16,6 \%$ \\
Mediana Empresa & $20,4 \%$ \\
Gran Empresa & $74,1 \%$ \\
\hline Estructura organizativa: empresas que modificaron de forma significativa su estructura & $25,9 \%$ \\
\hline No modificaron & $17,6 \%$ \\
Si modificaron & $82,4 \%$ \\
\hline Estructura Organizativa: tipo de cambio organizacional que introdujo su empresa & $15,3 \%$ \\
Nuevas prácticas de negocio para procedimientos organizacionales & $84,7 \%$ \\
No introdujo & $2,9 \%$ \\
Nuevos métodos de organización de responsabilidades y de toma de decisiones & \\
No introdujo & $97,1 \%$ \\
Nuevos métodos de organización del relacionamiento externo con otras firmas o & \\
instituciones públicas & $70,98 \%$ \\
No introdujo & $29,02 \%$ \\
\hline Estrategia de apoyo a la innovación: Realiza inversión en Investigación y Desarrollo & \\
\hline No invierte en I+D & $48,0 \%$ \\
Si Invierte en I+D & $27,0 \%$ \\
Liderazgo: importancia que tuvo para las actividades de innovación el área Administrativa & $13,5 \%$ \\
Alta & $11,6 \%$ \\
Media & \\
Baja & 73,7 \\
No importante & 26,3 \\
\hline Trabajadores y mandos medios: gasto en capacitación de personal & \\
No & $42,7 \%$ \\
Si & $16,1 \%$ \\
Trabajadores y mandos medios: importancia tuvo el objetivo de innovación "Mejorar la salud o seguridad ocupacional de sus \\
empleados" \\
Alta & $23,4 \%$ \\
Media & $17,9 \%$ \\
Baja & \\
No relevante &
\end{tabular}


Tabla 3. Determinantes Externos

\begin{tabular}{|c|c|c|c|}
\hline \multicolumn{2}{|c|}{ "Sistema de Gestión de calidad ISO 9001:2008" } & $\begin{array}{l}\text { No } \\
\mathrm{Si}\end{array}$ & $\begin{array}{l}48,5 \% \\
51,5 \%\end{array}$ \\
\hline \multicolumn{2}{|l|}{ "Programas Sectoriales" } & $\begin{array}{l}\text { No } \\
\text { Si }\end{array}$ & $\begin{array}{l}91,9 \% \\
8,1 \%\end{array}$ \\
\hline \multirow{2}{*}{\multicolumn{2}{|c|}{$\begin{array}{l}\text { "Calificación, registro de maquiladoras y autorización de los respectivos } \\
\text { programas de maquila" }\end{array}$}} & No & $93,6 \%$ \\
\hline & & $\mathrm{Si}$ & $6,4 \%$ \\
\hline \multicolumn{2}{|l|}{ "Jóvenes Productivos" } & $\begin{array}{l}\text { No } \\
\text { Si }\end{array}$ & $\begin{array}{l}91,7 \% \\
8,3 \%\end{array}$ \\
\hline \multicolumn{2}{|l|}{ "Innova Ecuador" } & $\begin{array}{l}\text { No } \\
\mathrm{Si}\end{array}$ & $\begin{array}{l}93,7 \% \\
6,3 \%\end{array}$ \\
\hline \multicolumn{2}{|c|}{ "SRRI ? Sistema de Registro de Renovación Industrial" } & $\begin{array}{l}\text { No } \\
\text { Si }\end{array}$ & $\begin{array}{l}94,5 \% \\
5,5 \%\end{array}$ \\
\hline \multicolumn{4}{|c|}{ Gobierno: La empresa recibió apoyo financiero gubernamental. } \\
\hline \multicolumn{3}{|c|}{$\begin{array}{l}\text { Si recibió apoyo } \\
\text { No recibió }\end{array}$} & $\begin{array}{l}22,0 \% \\
78,0 \%\end{array}$ \\
\hline \multicolumn{4}{|c|}{ Factores sociales y demográficos: importancia del objetivo de innovación "Reducir los impactos ambientales" } \\
\hline $\begin{array}{l}\text { Alta } \\
\text { Media } \\
\text { Baja } \\
\text { No relevante }\end{array}$ & & & $\begin{array}{l}53,1 \% \\
13,6 \% \\
13,3 \% \\
20,0 \%\end{array}$ \\
\hline \multicolumn{4}{|l|}{ Tecnología: La empresa adquirió. } \\
\hline \multicolumn{2}{|l|}{ Maquinaria y equipo } & $\begin{array}{l}\text { No } \\
\mathrm{Si}\end{array}$ & $\begin{array}{l}62,5 \% \\
37,5 \%\end{array}$ \\
\hline \multicolumn{2}{|l|}{ Hardware } & $\begin{array}{l}\text { No } \\
\text { Si }\end{array}$ & $\begin{array}{l}78,7 \% \\
21,3 \%\end{array}$ \\
\hline \multicolumn{2}{|l|}{ Software } & $\begin{array}{l}\text { No } \\
\text { Si }\end{array}$ & $\begin{array}{l}77,6 \% \\
22,4 \%\end{array}$ \\
\hline \multicolumn{2}{|l|}{ Tecnología desincorporada } & $\begin{array}{l}\text { No } \\
\text { Si }\end{array}$ & $\begin{array}{l}96,0 \% \\
4,0 \%\end{array}$ \\
\hline \multicolumn{4}{|c|}{ Entorno económico y variaciones de presupuesto: Importancia de "Falta de fondos dentro de la empresa } \\
\hline \multicolumn{3}{|c|}{$\begin{array}{l}\text { Alta } \\
\text { Media } \\
\text { Baja } \\
\text { No experimentado } \\
\end{array}$} & $\begin{array}{l}16,4 \% \\
12,2 \% \\
5,3 \% \\
66,1 \%\end{array}$ \\
\hline \multicolumn{4}{|c|}{ Cooperación, acuerdos y colaboraciones: la empresa ha cooperado para el desarrollo de innovación. } \\
\hline "Usuarios y ciudadanos" & $\begin{array}{l}\text { Si coopera } \\
\text { No coopera }\end{array}$ & & $\begin{array}{l}56,2 \% \\
43,8 \%\end{array}$ \\
\hline "Proveedores" & $\begin{array}{l}\text { Si coopera } \\
\text { No coopera }\end{array}$ & & $\begin{array}{l}55,6 \% \\
44,4 \%\end{array}$ \\
\hline "Consultores" & $\begin{array}{l}\text { Si coopera } \\
\text { No coopera }\end{array}$ & & $\begin{array}{l}41,2 \% \\
58,8 \%\end{array}$ \\
\hline "Competidores" & $\begin{array}{l}\text { Si coopera } \\
\text { No coopera }\end{array}$ & & $\begin{array}{l}19,4 \% \\
80,6 \%\end{array}$ \\
\hline "Otras empresas relacionadas" & $\begin{array}{l}\text { Si coopera } \\
\text { No coopera }\end{array}$ & & $\begin{array}{l}18,1 \% \\
81,9 \%\end{array}$ \\
\hline "Universidades" & $\begin{array}{l}\text { Si coopera } \\
\text { No coopera }\end{array}$ & & $\begin{array}{l}17,3 \% \\
82,7 \%\end{array}$ \\
\hline "Laboratorios/Empresas de I+D" & $\begin{array}{l}\text { Si coopera } \\
\text { No coopera }\end{array}$ & & $\begin{array}{l}15,7 \% \\
84,3 \%\end{array}$ \\
\hline "Organismos públicos CTI" & $\begin{array}{l}\text { Si coopera } \\
\text { No coopera }\end{array}$ & & $\begin{array}{l}6,9 \% \\
93,1 \%\end{array}$ \\
\hline "Oficina de propiedad intelectual" & $\begin{array}{l}\text { Si coopera } \\
\text { No coopera }\end{array}$ & & $\begin{array}{l}1,6 \% \\
98,4 \%\end{array}$ \\
\hline
\end{tabular}


Tabla 4. Correlación entre variables

\begin{tabular}{|c|c|c|c|c|c|c|c|c|c|c|c|c|c|c|c|}
\hline & Me-an. & Std. Dev & 1 & 2 & 3 & 4 & 5 & 6 & 7 & 8 & 9 & 10 & 11 & 12 & 13 \\
\hline 1. Innovación & 0,273 & 0,449 & 1 & & & & & & & & & & & & \\
\hline 2. Tamaño de la empresa & 1,894 & 0,914 & 0,1467 & 1 & & & & & & & & & & & \\
\hline 3. Estructura Organizacional & 0,364 & 0,485 & 0,1736 & $0,3316^{*}$ & 1 & & & & & & & & & & \\
\hline 5. Liderazgo & 0,621 & 0,489 & $0,4782^{*}$ & $0,2876^{*}$ & $0,3306^{*}$ & $0,4604^{*}$ & 1 & & & & & & & & \\
\hline 6. Trabajadores: capacitación & 0,409 & 0,495 & $0,5284^{*}$ & $0,5392^{*}$ & $0,2679^{*}$ & $0,3320^{*}$ & $0,6497^{*}$ & 1 & & & & & & & \\
\hline 7. Trabajadores: Salud y seguridad & 0,576 & 0,498 & $0,2503^{*}$ & 0,2377 & $0,2665^{*}$ & $0,3302^{*}$ & $0,7201^{*}$ & $0,4648^{*}$ & 1 & & & & & & \\
\hline 9. Gobierno: apoyo financiero & 0,318 & 0,469 & 0,0930 & $0,2593^{*}$ & 0,1598 & 0,2275 & $0,2652^{*}$ & 0,1594 & $0,4548^{*}$ & 0,1866 & 1 & & & & \\
\hline 10. Factores sociales: ambiente & 0,561 & 0,500 & 0,1309 & 0,1995 & 0,1615 & $0,3519^{*}$ & $0,6303^{*}$ & $0,3641^{*}$ & $0,8461^{*}$ & 0,1852 & $0,4737^{*}$ & 1 & & & \\
\hline 11. Tecnologia: adquisición & 0,606 & 0,492 & $0,3545^{*}$ & $0,3161^{*}$ & $0,3516^{*}$ & $0,5450^{*}$ & $0,7129^{*}$ & $0,5447^{*}$ & $0,7510^{*}$ & $0,3292^{*}$ & $0,4176^{*}$ & $0,7857^{*}$ & 1 & & \\
\hline 12. Entorno económico: falta de fondos & 0,455 & 0,502 & 0,1242 & 0,0732 & $0,2588^{*}$ & 0,1955 & $0,4619^{*}$ & 0,2307 & $0,4758^{*}$ & $-0,006$ & $0,2910^{*}$ & $0,4403^{*}$ & $0,5492^{*}$ & 1 & \\
\hline 13. Cooperación & 0,652 & 0,480 & $0,3765^{*}$ & $0,3704^{*}$ & $0,2884^{*}$ & $0,4206^{*}$ & $0,7399^{*}$ & $0,6085^{*}$ & $0,7233^{*}$ & $0,3439^{*}$ & $0,4313^{*}$ & $0,6980^{*}$ & $0,7770^{*}$ & $0,4761^{*}$ & 1 \\
\hline
\end{tabular}

* significancia $\mathrm{p}<0.05 . \mathrm{N}=66$ Observaciones

\section{Drivers internos}

El tamaño de la organización se ha clasificado por número de trabajadores[iv]. Así, 63\% de las empresas públicas corresponden a pequeña empresa, 20,4\% gran empresa, y $16,6 \%$ son mediana empresa. No existen microempresas de capital público, puede ser debido a dos razones fundamentales: a) burocracia como visión tradicional del Estado; b) costos de transacción asociados (Concha \& Naser, 2012).

Contrario a lo esperado en la Hipótesis 1, tamaño e innovación no tienen correlación significativa $(\mathrm{p}<0,05)$ en el caso ecuatoriano.

Sobre la estructura organizacional, los resultados muestran el porcentaje de empresas que realizaron cambios organizacionales y el tipo de modificación organizacional. Así, 25,9\% de las organizaciones realizaron modificaciones significativas en su estructura organizacional, 74,1\% no realizó modificación o no se consideran significativas. Los pequeños cambios que se dan día a día para solucionar problemas pequeños o demandas de ciudadanos específicos, no se consideran cambios organizacionales o innovaciones de proceso (Windrum \& García, 2008).

Sobre los tipos de modificaciones, $17,6 \%$ de las organizaciones públicas introdujo nuevas prácticas de negocio en los procedimientos organizacionales, 15,3\% utilizó nuevos métodos de organización de responsabilidades y toma de decisiones, mientras que 2,9\% realizó cambios organizativos para relacionamiento externo. Se propuso la existencia de correlación significativa entre modificaciones de estructura organizacional e innovación (Hipótesis 2). Los resultados no apoyan esta hipótesis, los cambios organizacionales no están correlacionados significativamente $(\mathrm{p}<0,05)$ con la innovación.

La Estrategia de apoyo a la innovación ha sido aproximada por el gasto o inversión en actividades de I $+\mathrm{D}$. Así, 29,02\% de las empresas públicas realizan inversión en actividades de I+D, mientras que 70,98\% no lo hace. Casi $30 \%$ de empresas públicas cuentan con una partida presupuestaria específica para actividades de $\mathrm{I}+\mathrm{D}$. Los resultados confirman la Hipótesis 3 existiendo una correlación significativa $(\mathrm{p}<0,05)$ entre innovación y estrategia de apoyo a la innovación en las empresas públicas de Ecuador.

El liderazgo se mide por la importancia del área administrativa en el desarrollo de innovaciones. Así, $48 \%$ de las empresas considera de alta importancia, 27\% indica media, 13,5\% baja. Estos resultados son consistentes con los trabajos de (Borins, 2001; Dunleavy \& Margetts, 2006; European Commission, 2010) donde los resultados oscilan entre el $25 \%$ y el $46 \%$. Los resultados apoyan la Hipótesis 4 ya que el liderazgo está significativamente $(\mathrm{p}<0,05)$ correlacionado con la innovación.

Para trabajadores y mandos medios los resultados muestran, el porcentaje de empresas que realizaron gastos de capacitación $26,3 \%$, y la importancia de la salud y seguridad ocupacional para el desarrollo de innovaciones, 
$48 \%$ de las organizaciones la considera de alta importancia, $27 \%$ media y $13,5 \%$ baja, $11,6 \%$ no relevante. Los resultados destacan la importancia de la satisfacción del trabajador y su relación positiva con innovación (Palmer \& Dunford, 2001; Montes, Moreno, \& Fernández, 2004) y además apoyan Hipótesis 5 y Hipótesis 6 , confirmándose la existencia de correlación significativa $(\mathrm{p}<0.05)$ entre capacitación, salud y seguridad e innovación.

\section{Drivers externos}

En relación al gobierno la encuesta muestra las empresas que han recibido apoyo financiero adicional, $22 \%$ y el conocimiento de las organizaciones sobre algunos instrumentos gubernamentales de apoyo a la innovación implementados por el Ministerio de Industrias y Productividad[v] (MIPRO). Así, el programa más difundido entre las empresas públicas es el "Sistema de Gestión de calidad ISO 9001:2008", 51,5\% de las organizaciones públicas lo conocen, mientras que los otros programas son menos conocidos, obteniendo valores entre 5,5\% y 8,3\%. Los resultados apoyan la Hipótesis 7, confirmando la existencia de correlación significativa $(\mathrm{p}<0,05)$ entre conocimiento de los programas gubernamentales de apoyo e innovación. Por otro lado, no se confirma la existencia de correlación significativa $(\mathrm{p}<0,05)$ entre apoyo financiero gubernamental e innovación (Hipótesis 8).

Respecto a los factores sociales y demográficos medidos por la importancia de reducir el impacto ambiental, muestran que, $53,1 \%$ de las empresas los consideran de alta importancia, $13,6 \%$ y $13,3 \%$ media y baja respectivamente y finalmente para $20 \%$ de las empresas no resulta relevante. Si bien los resultados encontrados respaldan las conclusiones de trabajos previos donde destaca el medio ambiente como determinante de la innovación (Dunleavy \& Margetts, 2006; Agolla \& Lill, 2013), al analizar la correlación entre factores ambientales e innovación, esta no es significativa $(\mathrm{p}<0,05)$ por lo que no apoya a la hipótesis planteada (Hipótesis 9).

La tecnología puede ser adquirida de manera incorporada (maquinaria, equipo, etc.) o desincorporada (patentes, planos, etc.). En los dos casos requiere de conocimiento al interior de la organización para lograr desarrollo de innovación (Hauknes \& Knell, 2009). Así, las empresas públicas adquieren: maquinaria y equipo $37,5 \%$, hardware $21,3 \%$, software $22,4 \%$ y tecnología desincorporada $4 \%$. Los resultados obtenidos para Ecuador confirman la importancia que tiene la gestión tecnológica para la innovación (Pärna \& von Tunzelmann, 2007; Hughes, Moore, \& Kataria, 2011) ya que apoyan la hipótesis planteada sobre la existencia de correlación significativa $(\mathrm{p}<0,05)$ entre tecnología e innovación (Hipótesis 10).

Los resultados para entorno económico y variaciones de presupuesto muestran que $66,1 \%$ de las empresas "No ha experimentado" falta de recursos. Esto podría estar influenciado por el año de aplicación de la encuesta. En 2011 la tasa real de crecimiento del producto interno bruto (PIB) en Ecuador fue del 7,9\% (Banco Mundial, 2016), no existía falta de recursos en las instituciones públicas. Sin embargo 16,4\% y 12,2\% de las empresas públicas lo consideran como obstáculo de alta y media importancia respectivamente. Los resultados no confirman para el caso de Ecuador, existencia de correlación significativa $(p<0,05)$ entre falta de recursos e innovación (Hipótesis 11).

Respecto a cooperación para desarrollo de innovación, se observan tres niveles de cooperación:

- Fuerte: Clientes y consumidores $56,2 \%$, Proveedores $55,6 \%$ y Consultores $41,2 \%$;

- Media: Competidores 19,4\%, Otras empresas relacionadas 18,1\%, Universidades 17,3\% y Laboratorios/Empresas de I+D 15,7\%;

- Débil: Organismos Públicos de CTI 6,9\% y Oficina de propiedad intelectual 1,6\%. 
Los resultados ponen de manifiesto la existencia de socios estratégicos para desarrollo de innovación en instituciones públicas (Arundel et al., 2015). Destacan como agentes para cooperación los usuarios y ciudadanos, proveedores en línea con los trabajos previos (Borins, 2001, 2002; Dunleavy \& Margetts, 2006).

Las consultoras o empresas intensivas en conocimiento (KIBS por sus siglas en inglés) se consideran facilitadores, fuente de innovación, productoras y coproductoras de innovación, difusión y uso de tecnología (Hauknes \& Knell 2009). Destaca que universidades, laboratorios y empresas de investigación y desarrollo (I+D) sean cooperación media, son importantes para la innovación (Mulgan, 2007; European Commission, 2010). Los resultados apoyan la hipótesis planteada, sobre existencia de correlación significativa $(\mathrm{p}<0,05)$ entre cooperación e innovación (Hipótesis 12) en las empresas públicas ecuatorianas.

A continuación, se presenta un cuadro resumen de las hipótesis aceptadas y rechazadas: 
Tabla 5. Resumen de hipótesis

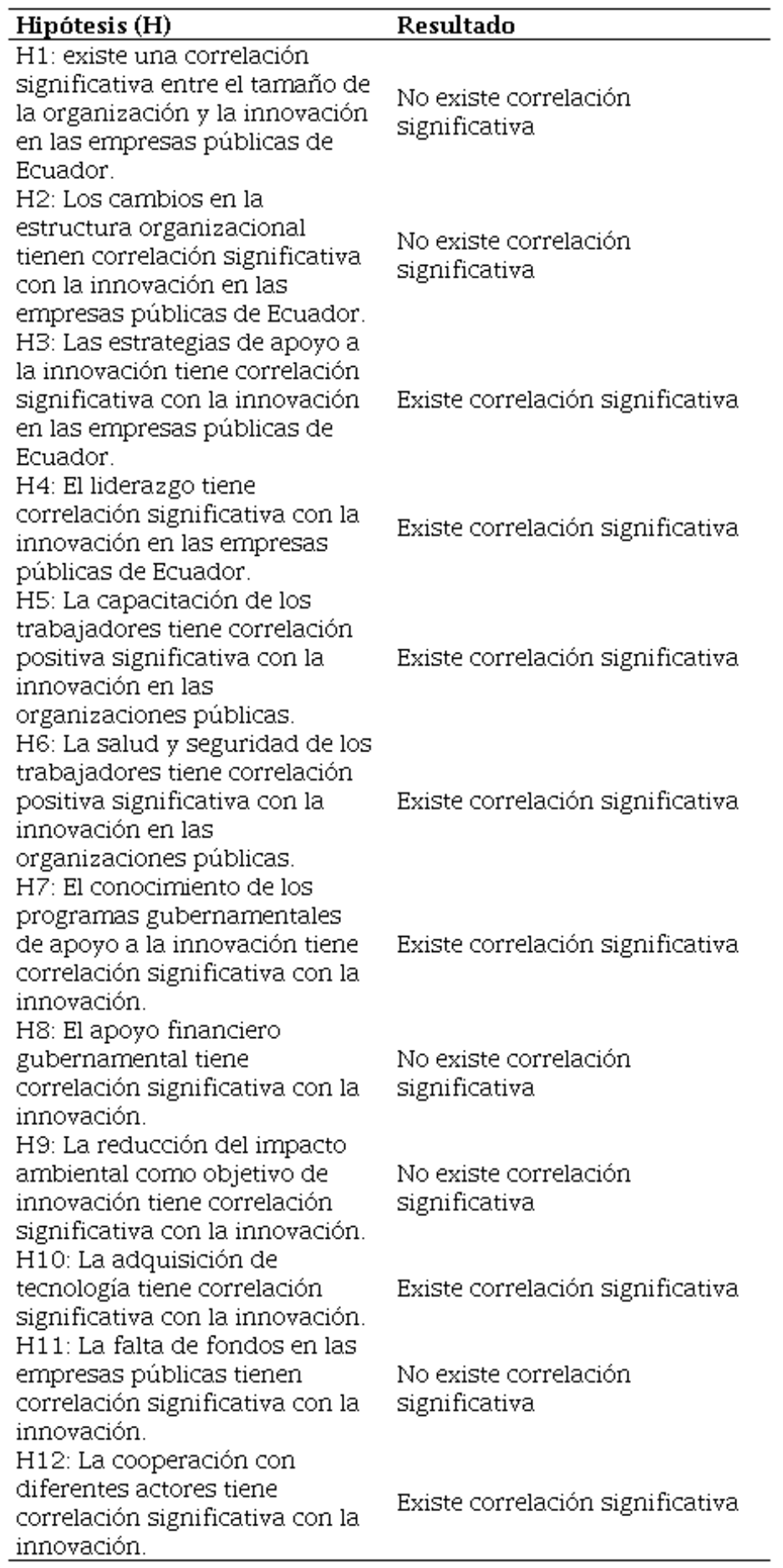

\section{CONCLUSIONES}

La revisión teórica realizada permite proponer como principales determinantes de la innovación pública en las empresas ecuatorianas los siguientes: 
Internos: Tamaño de la organización (Fernández \& Wise, 2010; Palmer \& Dunford, 2001); estructura organizacional (Palmer \& Dunford, 2001; Laegreid et al., 2011; Kim, 2010); estrategia interna de apoyo a la innovación (Borins, 2001; Kim, 2010; ANAO, 2009; Bysted \& Jespersen, 2014); liderazgo (Vigoda-Gadot et al., 2008; Agolla \& Lill, 2013; Borins, 2002); trabajadores y mandos medios (Saari, Lehtonen, \& Toivonen, 2015).

Externos: Gobierno, entorno político y legal (Walker, 2008; Agolla \& Lill, 2013; Fernández \& Wise, 2010); Factores sociales y demográficos (Agolla \& Lill, 2013; Marr, 2009; UN Millennium Project, 2005); Tecnología (Arduini et al., 2010; Pärna \& von Tunzelmann, 2007); Entorno económico y variaciones de presupuesto (Marr, 2009; Agolla \& Lill, 2013; Potts \& Kastelle, 2010; Mulgan \& Albury, 2003); Cooperación, Acuerdos y Colaboraciones (Goh, 2005; Bugge, Mortensen, \& Bloch, 2011; Bommert, 2010; OECD, 2010). Esta clasificación se la realiza de acuerdo al origen de cada determinante.

Sin ser el objetivo fundamental de esta investigación, este trabajo permite mostrar empíricamente la existencia de innovación radical e incremental (Schumpeter, 1947) en las empresas públicas del Ecuador. Los datos indican que las empresas públicas en Ecuador realizan tres tipos de innovación: Producto, proceso y servicio con diferentes niveles de novedad, esto confirma la existencia e importancia de la innovación pública, reforzando de esta manera los trabajos previos (Mazzucato \& Dosi, 2006; Mazzucato, 2014; Leslie, 2000).

A pesar de que se han generado indicadores para cada uno de los determinantes propuestos, no todos los determinantes se correlacionan significativamente con la innovación. Así, los determinantes que tienen correlación significativa $(\mathrm{p}<0,05)$ con la innovación en empresas públicas de Ecuador son:

Internos: Estrategia de apoyo a la innovación, fundamental para la innovación, confirma los trabajos de (Aubert et al., 2010; Arundel et al., 2015). Liderazgo, confirma los trabajos de Agolla an Lill (2013), Bloch and Bugge (2013), Mulgan (2007) y Walker (2006). Trabajadores y mandos medios (capacitación, salud y seguridad) apoya trabajos de Borins (2002); Pärna y von Tunzelmann (2007); Sánchez y Castrillo (2006); Palmer y Dunford (2001); Montes, Moreno y Fernández (2004).

Externos: Gobierno mediante programas de apoyo, confirmando su importancia y los trabajos de Porter y Stern (2001), OECD (2010) y Agolla y Lill (2013). Tecnología, apoya los resultados de Goh (2005), Keller (2004), Lonti \& Verma (2003), Marr (2009) y Mulgan y Albury (2003). Cooperación, acuerdos y colaboraciones, confirma los trabajos de OECD (2010), Bommert (2010), Szkuta, Pizzicannella y Osimo (2014) y Sorensen y Torfing (2012).

Los determinantes como el tamaño de la empresa, la estructura organizacional, el gobierno (apoyo financiero), los factores sociales (ambiente) y el entorno económico (falta de fondos) no están correlacionados significativamente con la innovación en empresas públicas de Ecuador.

Sobre las limitaciones de este trabajo cabe señalar que es un trabajo de corte transversal, debido a la falta de periodicidad en la encuesta de innovación de Ecuador, por lo que la información que aporta es estática y no permite ver la evolución de la innovación pública. La muestra es pequeña por lo que la falta de información puede ocasionar ruido afectando los resultados.

Como futuras líneas de investigación es posible realizar análisis econométrico a fin de identificar la significatividad, probabilidad, ajuste de los determinantes ante la innovación de las empresas públicas y el impacto de la innovación pública en el crecimiento económico.

\section{ReFERENCIAS}

Agolla, Joseph E, Lill, J. B. Van. (2013). Public Sector Innovation Drivers\#: A Process Model. Journal of Social Science 34(2), 165-176.

Agolla, Joseph E, Lill, J B Van. (2017). Insights into Kenya’s public sector innovation\#: the case of managers. International Journal of Innovation Science 9(3), 225-143. doi:10.1108/IJIS-11-2016-0049. 
Alberti, Adriana, Bertucci, Guido. (2006). Replicating Innovations in Governance: An Overview. En Innovations in Governance and Public Administration: Replicating what works, 1-21. New York: Department of Economic and Social Affairs.

Anao. (2009). Innovation in the public sector: Enabling Better Performance, Driving New Directions. Canberra: Commonwealth of Australia.

Arduini, D., Belotti, F., Denni, M., Giungato, G., Zanfei, A. (2010). Technology adoption and innovation in public services the case of e-government in Italy. Information Economics and Policy, 22(3), 257-275. doi:10.1016/ j.infoecopol.2009.12.007.

Arundel, Anthony, Casali, Luca, Hollanders, Hugo. (2015). How European public sector agencies innovate: The use of bottom-up, policy-dependent and knowledge-scanning innovation methods. Research Policy, 44(7), 1271-1282. doi:10.1016/j.respol.2015.04.007.

Arundel, Anthony, Dorothea, Huber. (2013). From too little to too much innovation? Issues in measuring innovation in the public sector. Structural Change and Economic Dynamics, 27(1), 146-159. doi:10.1016/ j.strueco.2013.06.009.

Aubert, Jean-Eric, Chen, Derek, Kim, Ronald, Kuznetzov, Yevgeny, Larsen, Kurt, Theus, Florian, Utz, Anuja, White, Justine. (2010). Innovation Policy A Guide for Developing Countries. Washington D.C.: The World Bank. doi:10.1596/978-0-8213-8269-1.

Banco Mundial. (2016). Indicadores del desarrollo mundial. Ecuador. Recuperado de: http://databank.bancomundial .org $/$ data $/$ reports.aspx ?source $=2 \&$ country $=E C U \&$ series $=\&$ period $=$.

Bartlett, D, Dibben, P. (2010). Public Sector Innovation and Entrepreneurship\#: Case Studies from Local Government. Local Government Studies, 28(4), 107-121. doi:10.1080/714004159.

Bingham, Richard D. (1978). Innovation, Bureaucracy, and Public Policy: A Study of Innovation Adoption by Local Government. The Western Political Quarterly, 31(2), 178-205. doi:10.1177/106591297803100203.

Bloch, Carter, Markus, M. Bugge. (2013). Public sector innovation - From theory to measurement. Structural Change and Economic Dynamics, 27(4), 133-145. doi:10.1016/j.strueco.2013.06.008.

Bommert, Ben. (2010). Collaborative Innovation in the Public Sector. International Public Management Review, $11(1), 15-33$.

Borins, Sandford. (2001). Encouraging innovation in the public sector. Journal of Intellectual Capital, 2(3), 310-319. doi:10.1108/14691930110400128.

Borins, Sandford. (2002). Leadership and innovation in the public sector. Leadership \& Organization Development Journal, 23(1), 467-476. doi:10.1108/01437730210449357.

Boyne, George a., Gould-Williams, Julian S., Law, Jennifer, \& Walker, Richard M. (2005). Explaining the adoption of innovation: An empirical analysis of public management reform. Environment and Planning C: Government and Policy, 23(3), 419-435. doi:10.1068/c40m.

Brandão, Soraya Monteiro, Bruno-Faria, Maria De Fátima. (2013). Inovação no setor público: análise da produção científica em periódicos nacionais e internacionais da área de administração. Revista de Administração Pública, 47(d), 227-248. doi:10.1590/S0034-76122013000100010.

Bugge, Markus M., Mortensen, Peter, Bloch, Carter. (2011). Measuring Public Innovation in the Nordic Countries: Report on the Nordic Pilot Studies. Copenhagen: Danish Centre for Studies in Research and Research Policy.

Bysted, Rune, Risom, Jespersen. (2014). Exploring Managerial Mechanisms that Influence Innovative Work Behaviour. Public Management Review, 16(2), 217-241. doi:10.1080/14719037.2013.806576.

Concha, G, Alejandra, Naser. (2012). El desafio hacia el gobierno abierto en la hora de la igualdad. Santiago de Chile: CEPAL.

Cruz, Silvia, Sonia, Paulino. (2013). Public service innovation and evaluation indicators. Journal of Technology Management and Innovation, 8(2), 285-297. 
Damanpour, Fariborz, Marguerite, Schneider. (2006). Phases of the Adoption of Innovation in Organizations: Effects of Environment, Organization and Top Managers. British Journal of Management, 17(3), 215-236. doi:10.1111/ j.1467-8551.2006.00498.x.

Damanpour, Fariborz, Richard, M. Walker, Avellaneda, Claudia N. (2009). Combinative effects of innovation types and organizational Performance: A longitudinal study of service organizations. Journal of Management Studies, 46(4), 650-675. doi:10.1111/j.1467-6486.2008.00814.x.

Djellal, Faridah, Gallouj, F. (2012). Two decades of research on innovation in services: Which place for public services? En 1st International EIBURS-TAIPS TAIPS Conference on: Innovation in the public sector and the development of e-service.

Dunleavy, Patrick, Margetts, Helen. (2006). Achieving innovation in central government organisations. London: The Stationery Office-National Audit Office.

European Commission. (2010). Innobarometer 2010: Analytical Report Innovation in Public Administration. Brussels, Belgium.

Farah, Marta Ferreira Santos. (2008). Disseminação de inovações e políticas públicas e espaço local. Revista Organizaçôes \& Sociedade, 15(45), 107-126.

Fernández, Sergio, Wise, Lois. (2010). An exploration of why public organizations "ingest" innovations. Public. Public Administration Journal, 88(4), 979-998. doi:10.1017/CBO9781107415324.004.

Ferreira, João J. M., Fernandes, Cristina I., Alves, Helena, Raposo, Mário L. (2015). Drivers of innovation strategies: Testing the Tidd and Bessant (2009) model. Journal of Business Research, 68(7), 1395-1403. doi:10.1016/ j.jbusres.2015.01.021.

Goh, Andrew L.S. (2005). Promoting innovation in aid of industrial development: the Singaporean experience. International Journal of Public Sector Management, 18(3), 216-240. doi:10.1108/09513550510591524.

Hartley, Jean. (2005). Innovation in governance and public services: Past and present. Public money and management, $1(1), 27-35$.

Hauknes, Johan, Knell, Mark. (2009). Embodied knowledge and sectoral linkages: An input-output approach to the interaction of high- and low-tech industries. Research Policy, 38(3), 459-469. doi:10.1016/j.respol.2008.10.012.

Hughes, Alastair, Moore, Kyla, Kataria, Nimesh. (2011). Innovation in Public Sector Organisations: A pilot survey for measuring innovation across the public sector. NESTA Index report. London.

Jibir, Adamu, Abdu, Musa. (2017). Foreign Direct Investment - Growth Nexus: The Case of Nigeria. European Scientific Journal, 13(1), 304-318. doi:10.19044/esj.2017.v13n1p304.

Kattel, Rainer. (2015). What would Max Weber Say about Public-Sector Innovation? The NISP Acee Journal of Public Administration and Policy, 8(1), 9-19.

Keller, Wolfgang. (2004). International Technology Diffusion. Journal of Economic Literature, 42(3), 752-782. doi: $10.1257 / 0022051042177685$.

Kim, Younhee. (2010). Stimulating Entrepreneurial Practices in the Public Sector: The Roles of Organizational Characteristics. Administration \& Society, 42(7), 780-814. doi:10.1177/0095399710377432.

Koch, Per, Hauknes, Johan. (2005). On innovation in the public sector. PUBLIN Innovation in the Public Sector. V. D20. Oslo: NIFU STEP.

Laegreid, P., P. G. Roness, Verhoest, K. (2011). Explaining the Innovative Culture and Activities of State Agencies. Organization Studies, 32(10), 1321-1347. doi:10.1177/0170840611416744.

Leslie, Stuart. (2000). The Biggest" Angel" of Them All: The Military and the Making. En Understanding Silicon Valley: The anatomy of an Entrepreneurial Region, editado por M Kenny, 44-67. Standford: Standford University Press.

Lonti, Z. A., Verma, A. B. (2003). The Determinants of Flexibility and Innovation in the Government Workplace: Recent Evidence from Canada. Journal of Public Administration Research and Theory, 13(3), 283-310. doi:10.1093/jopart/mug025.

Love, James H., Stephen, Roper, Priit, Vahter. (2014). Dynamic complementarities in innovation strategies. Research Policy, 43(10), 1774-1784. doi:10.1016/j.respol.2014.05.005. 
Anderson Argothy Almeida, et al. Determinantes de Innovación Pública en Ecuador: Un Análisis Descr...

Luke, Belinda, Verreynne, Martie-Louise, Kearing, Kate. (2010). Innovative and entrepreneurial activity in the public sector\#: The changing face of public sector institutions. Innovation: management, policy \& practice, 12(2), 138-153.

Marr, Bernard. (2009). Managing and Delivering Performance: How Government, Public Sector and Not-ForProfit Organisations can Measure and Manage what Realy Matters. Oxford: Elsevier Ltda. doi:10.1016/ B978-0-7506-8710-2.00027-2.

Mazzucato, Mariana. (2014). El Estado emprendedor: mitos del sector público frente al privado. Primera Ed. Barcelona: RBA Libros.

Mazzucato, Mariana, Dosi, Giovanni. (2006). Knowledge accumulation and industry evolution: The case of PharmaBiotech. Cambridge: Cambridge University Press.

Montes, Francisco Javier Lloréns, Moreno, Antonia Ruiz, Fernández, Luis Miguel Molina. (2004). Assessing the organizational climate and contractual relationship for perceptions of support for innovation. International Journal of Manpower, 25(2), 167-180. doi:10.1108/01437720410535972.

Moon, Myung J, de Leon, Peter. (2001). Municipal reinvention: Managerial values and diffusion among municipalities. Journal of Public Administration Research and Theory 11(3), 327-351.

Moore, Mark. (2005). Break-through innovations and continuous improvement: Two different models of innovative processes in the public sector. Public Money and Management 25. Taylor \& Francis.

Morcillo, P., Rodríguez-Antón, J. M., Rubio, L. (2007). Corporate culture and innovation: in search of the perfect relationship. International Journal of Innovation and Learning, 4 (6), 547-570.

Moussa, Mahmoud, Mcmurray, Adela, Muenjohn, Nuttawuth. (2018). Innovation in public sector organisations. Cogent Business \& Management, 5(1), 1-12. doi:10.1080/23311975.2018.1475047.

Mulgan, Geoff. (2007). Ready or not? Taking Innovation in the Public Sector Seriously. London: NESTA.

Mulgan, Geoff, Albury, David. (2003). Innovation in the public sector. London: Strategy Unit, Cabinet Office.

Nonaka, I, Takeuchi, H. (1995). The knowledge-creating company: How Japanese companies create the dynamics of innovation. Oxford: Oxford University Press.

OECD. (2005). Manual de Oslo: Guia para la recolección e interpretacion de datos de innovación. Tercera ed. Paris: OECD Organisation for Economic Co-operation and Development.

OECD. (2010). Innovation to Strengthen Growth and Address Global and Social Challenges. Ministerial report on the OECD Innovation Strategy. Ministerial report on the OECD Innovation Strategy.

Palmer, I, Dunford, R. (2001). The diffusion of Managerial Innovations: A Comparison of Australian Public and Private Sector Take-up Rates of New Organizational Practices. International Public Management Journal, 4(1), 49-64. doi:10.1016/s1096-7494(01)00039-3.

Pärna, Ott, Von Tunzelmann, Nick. (2007). Innovation in the public sector: Key features influencing the development and implementation of technologically innovative public sector services in the UK, Denmark, Finland and Estonia. Information Polity: The International Journal of Government \& Democracy in the Information Age 12, 109-125. doi:Article.

Pearce, John A., Robinson, Richard. (2003). Strategic Management: Formulation, Implementation, and Control. 8th Editio. New York: McGraw Hill.

Porter, M. E., Stern, S. (2001). National Innovative Capacity. Harvard Business Review, 37(9), 1465-1479. doi:10.1016/j.respol.2005.04.009.

Potts, Jason, Kastelle, Tim. (2010). Public sector innovation research: What's next? Innovation: management, policy \& practice, 12(2), 122-137. doi:10.1145/2072069.2072100.

Rogers, Everett M. (1976). New Product Adoption and Diffusion. Journal of Customer Research, 2(4), 290-301. doi:10.1086/208642.

Saari, Eveliina, Lehtonen, Mikko, Toivonen, Marja. (2015). Making bottom-up and top-down processes meet in public innovation. Service Industries Journal, 35(6), 325-344. doi:10.1080/02642069.2015.1003369. 
Sánchez, M. Paloma, Castrillo, Rocío. (2006). La tercera edición del Manual de Oslo: Cambios e Implicaciones. Una Perspectiva de Capital Intelectual. Revista I+D, 35(1), 1-16.

Sarros, James C., Cooper, Brian K., Santora, Joseph C. (2008). Through Transformational Leadership and Organizational Culture. Journal of Leadership \& Organizational Studies, 15(2), 145-158. doi: $10.1177 / 1548051808324100$.

Schumpeter, J. A. (1947). The creative response in economic history. The Journal of Economic History, 7(2), 149-159.

Sorensen, Eva, Torfing, Jacob. (2012). Introduction Collaborative Innovation in the Public Sector. The innovation Journal: The Public Sector Innovation Journal, 17(1), 1-14.

Szkuta, Katarzyna, Pizzicannella, Roberto, Osimo, David. (2014). Collaborative approaches to public sector innovation: A scoping study. Telecommunications Policy, 38 (5-6), 558-567. doi:10.1016/j.telpol.2014.04.002.

Torugsa, Nuttaneeya Ann, Arundel, Anthony. (2015). The Nature and Incidence of Workgroup Innovation in the Australian Public Sector: Evidence from the Australian 2011 State of the Service Survey. Australian Journal of Public Administration 75(2), 202-221. doi:10.1111/1467-8500.12095.

UN Millennium Project. (2005). Innovation: applying knowledge in development. UN Millennium Project Task Force on Science Technology and Innovation Earthscan. V. 1. London: UN Milenium Project.

United Nations. (2006). Innovations in Governance and Public Administration: Replicating what works. New York: Department of Economic and Social Affairs.

Vigoda-Gadot, Eran, Shoham, Aviv, Schwabsky, Nitza, Ruvio, Ayalla. (2008). Public sector innovation for Europe: A multinational eight-country exploration of citizens' perspectives. Public Administration, 86(2), 307-329. doi:10.1111/j.1467-9299.2008.00731.x.

Walker, Richard M. (2006). Innovation type and diffusion: An empirical analysis of local government: Public Administration. Public Administration, 84(2), 311-335. doi:10.1111/j.1467-9299.2006.00004.x.

Walker, Richard M. (2008). An Empirical Evaluation of Innovation Types and Organizational and Environmental Characteristics: Towards a Configuration Framework. Journal of Public Administration Research and Theory, 18(4), 591-615. doi:10.1093/jopart/mum026.

Windrum, Paul, García, Manuel. (2008). A neo-Schumpeterian model of health services innovation. Research Policy, 37(4), 649-672. doi:10.1016/j.respol.2007.12.011.

\section{BY-NC-ND}

